\section{Twenty Rooms in it}

Mrs. H. Rodenberg, Kinloch

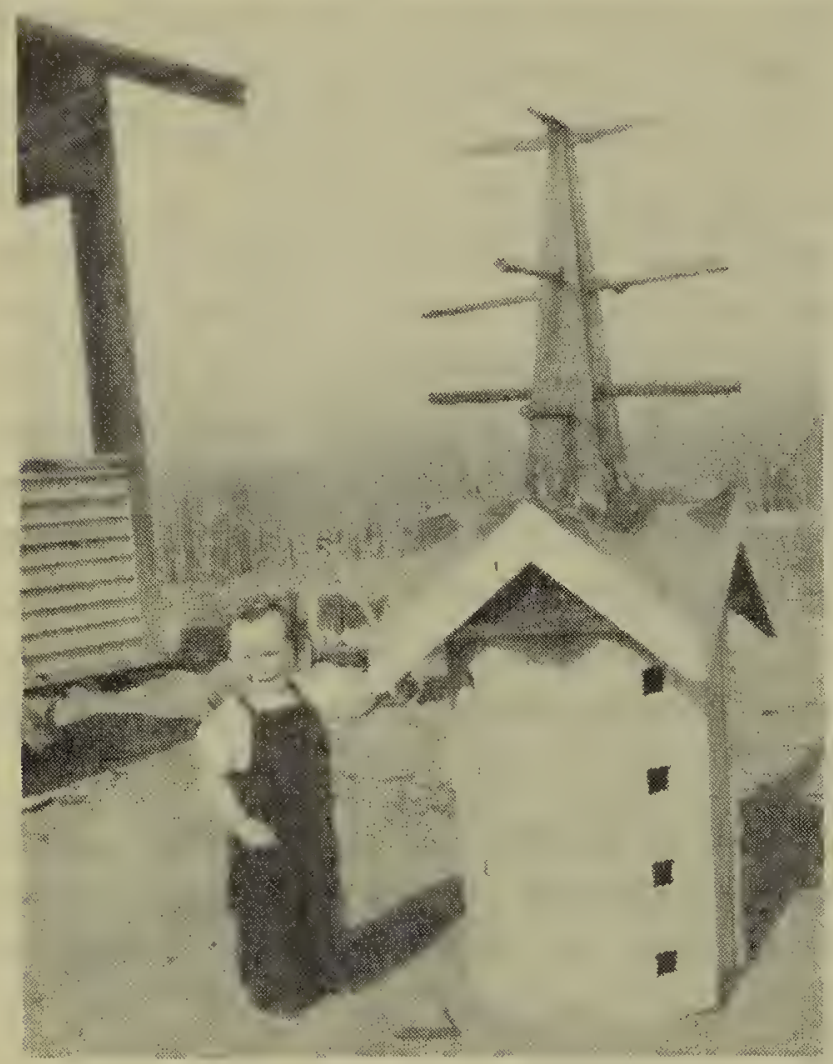

$\mathbf{T}$

HE accompanying photograph is

a picture of my Purple Martin house. The picture was taken four years ago, just after I had made and painted it. It has 20 separate rooms. The first year it was put up the Martins came and looked it over but did not nest in it. The second year we had four pair. Last year there were sixteen pair.

I love to watch the birds and every spring I get the urge to make at least one new bird house. This spring I plan on making a Bluebird house. There are quite a few of them around here. One pair always nests in a bluff near the house.

We also have Cliff Swallows. They have built such beautiful bottleshaped mud nests under the eaves of our house! I could spend hours just watching them.

The Hummingbird comes to my window-box regularly. This summer I'm going to put honey out for them, as Madeline B. Runyan mentioned in the last issue of the BLUE JAY.

Blue Jays are plentiful around here. They often come and feed outside the window, where I have a feeding tray for the Chickadees.

\section{PURPLE MARTINS} Bryan J. Isinger, Wakaw

${ }^{F}$ all the birds which will establish themselves near the farm home, I think the Purple Martin is the most interesting.

Last summer over thirty pairs established themselves in my father's farmyard, one mile south of Wakaw. They made their mud nests on the gable end of every building in the yard. Unfortunately, the wet summer we experienced caused many of the nests to fall to the ground. At present I am busy building apartments for their use upon the arrival of spring.

The Purple Martin is the only bird which will occupy a nesting box in colony. Hence it is useless to build bird houses of more than one compartment for other species than Martins.

I encouraged my last year's school class to build bird houses according to accepted standards of size, color of paint, etc. I accepted a Bluebird and a 4-roomed Martin house. Fortunately, both houses were occupied. Two families of Martins moved into one. I hope the remaining two rooms will also be used this year.

Purple Martins will return year after year to an established dwelling. Upon their return in the spring to an ancestral dwelling, intruders such as sparrows are rudely ejected. This often becomes a community effort. I have been told that the intruder is sometimes literally plastered with mud into complete confinement which, of course, leads only to death. Can any member substantiate this story? The other method of ejection, and one that I have observed, is where the intruder is showered with a hail of well-aimed pecks.

The Purple Martin is very often mistaken for the Barn Swallow. Both species will build nests of mud, enjoy human companions, belong to the Swallow family and hate cats-but here the similarity stops. The best means of recognition is the tail. The Barn Swallow naturally sports the famed "swallow - tail." Mounted species of these and other birds may be loaned from the National Museum at Ottawa.

Let us return the friendly gestures of these birds by inducing them to our premises with correct and well-built nesting boxes. 